\title{
Atravessamentos decoloniais da fotografia contemporânea negra sul-africana ${ }^{1}$
}

\author{
Fernando Gonçalves' \\ https://orcid/org/0000-0003-4886-3166 \\ Daniel Meirinho" \\ https://orcid.org/0000-0002-4658-5556 \\ I - Universidade Estadual do Rio de Janeiro. \\ Rio de Janeiro (RJ). Brasil. \\ II - Universidade Federal do Rio Grande do Norte. \\ Natal (RN). Brasil.
}

Resumo: As imagens do artista visual Kgomotso Neto revelam práticas narrativas e estéticas decoloniais africanas representadas a partir de novos marcadores de liberdade e do registro da vida cotidiana nas townships e centros urbanos da África do Sul. O artigo faz uma leitura dos lugares, simbologias e identidades a partir das suas fotografias, enfatizando os modos como a negritude é percebida e construída através de uma lente que dá a ver novas formas de contestação do legado colonial. A partir da análise de dois projetos do artista, o texto argumenta que seu trânsito por distintas referências e linguagens e sua relação íntima com o cotidiano urbano lhe permitem realizar jogos com as representações de corpos e de espaços, convidando-nos a perceber estilos de vida, de liberdade e de moda como lugares de luta e de resistência, com os quais busca apontar e ultrapassar lacunas e opressões coloniais.

Palavras-chaves: fotografia; África do Sul; arte contemporânea negra; decoIonialidade; Kgomotso Neto. 


\begin{abstract}
Decolonial crossings of contemporary black South African photography - The images by the visual artist Kgomotso Neto reveal African decolonial narratives and aesthetic practices represented by new markers of freedom and by the record of everyday life in South African townships and urban centers. The article observes how places, symbols and identities are taken in his photographs, emphasizing the ways in which blackness is perceived and constructed through a lens which reveals new ways of contesting the colonial legacy. Based on the analysis of two of his artistic projects, the text argues that his transit through different references and languages and his intimate relationship with urban daily life allow him to play games with the representations of bodies and places, inviting us to perceiving lifestyles, freedom and fashion as space of struggle and resistance, with which the artist seeks to point out and overcome gaps and colonial oppressions.
\end{abstract}

Keywords: photography; South Africa; contemporary black art; decolonial; Kgomotso Neto.

\title{
Introdução
}

Fotografias de um casal posando para o que se assemelharia a um tradicional ensaio editorial de moda ou imagens que documentam o cotidiano dos transportes coletivos na cidade de Joanesburgo nos convidam a discutir sobre cultura urbana, raça e africanidade no contexto das atuais lutas, resistências, confrontos políticos e estéticos na África do Sul. Nos trabalhos fotográficos de muitos jovens artistas contemporâneos negros, algumas definições identitárias e subjetivas forjadas por anos de segregação racial estão sendo revistas hoje, a partir de tensionamentos que dão espaço para novas formas de discussão política em que o corpo racializado e modos de vida locais são afirmados e passam a ocupar um lugar importante na construção de imaginários sociais heterogêneos e pluriversais.

Sobretudo no primeiro caso - das imagens posadas e simuladas de um salão de beleza — , o cabelo e a relação de embelezamento cotidiano são exibidos com o objetivo de reformular estereótipos e, ao mesmo tempo, de afirmar novos marcadores estéticos e expressivos que podemos identificar como decoloniais (MIGNOLO, 2010), no contexto de uma fotografia contemporânea negra sul-africana (GREEN; THOMAS, 2014). Por marcadores estéticos e expressivos estamos entendendo vetores de reconhecimento de modalidades de percepção e de enunciação que recusam as configurações eurocêntricas modernas e que estamos chamando aqui de decolonais.

Compreendemos que existe uma pluralidade de usos e significados para o termo decolonial (e também para anti-colonial e contra-colonial). Porém, mais 
do que desejar encontrar demarcações conceituais precisas, acionamos seu uso aqui para tratar de experiências comunicativas que falam de sujeitos e modos de vida que não operam (social, cultural, política, estética ou subjetivamente) no regime de uma colonialidade de poder de matriz eurocêntrica. A tais experiências comunicativas corresponderiam outras formas de percepção e de sensibilidade, que chamaremos aqui de uma experiência estética decolonial. Inscritas nessa chave de leitura, essas experiências são analisadas neste texto a partir das concepções de autores como Walter Mignolo, Aníbal Quijano, Maldonado-Torres, Catherine Walsh, Pedro Gómez, Madina Tlostanova, entre outros, ligados a uma corrente de pensamento político e epistemológico que surge no final dos anos 90 com o Grupo Modernidade/ Colonialidade. Essa corrente é movida pelo desejo de desmoronamento das dinâmicas de opressão, apagamento e genocídio que afligiu e ainda incide sobre os sujeitos e territórios colonizados. São respostas epistêmicas transmodernas que buscam habitar formas de saberes e práticas fronteiriças, como sugeriu Mignolo (2015), de corporeidade ancestral, histórica e cultural através do resgate de memórias e de confrontamentos.

É nesse sentido que as imagens posadas e simuladas de um salão de beleza evocadas no início do texto serão consideradas aqui como expressão de uma estética decolonial. Elas fazem parte da exposição Turning Heads, do fotógrafo Kgomotso Neto Tleane, aberta em novembro de 2019 na Galeria Artivist, em Joanesburgo. Os retratos posados em estúdio reproduzem uma prática cotidiana urbana e das townships ${ }^{2}$ de cuidar da aparência e, em especial, do cabelo, como uma poderosa marca de negritude (KILOMBA, 2019) que por muito tempo esteve no inconsciente da branquitude como a "maldição corpórea" (FANON, 1967, p. 122). Não por acaso, o pensador martinicano afirmava que primeiro ataque colonial se dá no corpo físico dos sujeitos colonizados, bem como no campo simbólico a partir de uma régua moral e normativa europeia. Já os registros que compõem as narrativas visuais sobre o cotidiano dos transportes coletivos no centro de Joanesburgo apresentados no projeto Taxi Rank permitem entrecruzar as formas atuais de ocupação do espaço urbano com os contextos das lutas raciais e de classe negadas pelo regime do apartheid.

Como veremos, o que poderia ser apenas o registro da vida diária em Joanesburgo ganha novos significados nos trabalhos de Kgomotso Neto e 
no contexto atual da fotografia e das artes visuais sul-africanas, na tentativa de subverter e contestar o regime racializado de representação (HALL, 2016). Neto faz parte de uma geração de jovens artistas do pós-apartheid que vive e cria dentro de uma perspectiva que bell hooks³ (2019) chama "da margem para o centro". Assim como outros artistas e fotógrafos contemporâneos negros como Mohau Modisakeng, Andrew Tshabangu e Zanele Muholi, que ganharam projeção com exposições internacionais em bienais, Neto percorre a mesma jornada que passa por estratégias de documentação que retrata e captura práticas da vida cotidiana próximas a um realismo fantástico e fabulatório (NYONG'O, 2019).

Assim, novas formas de expressão artística vêm se configurando, como afirma Dona Marimba Richards (1994), através de um vocabulário íntimo repleto de significados quase sempre suprimidos de uma gramática visual eurocêntrica (QUIJANO, 2002), mas que hoje é explorado de forma poética e política por meio de temas da história pública interligada às histórias pessoais. Nessas explorações, o corpo e espaço passam a ser uma ferramenta de resistência e de pertencimento no interior do legado de desigualdade e de reterritorialização na África do Sul contemporânea.

O interesse de Neto pelo cotidiano urbano e pelas transformações dos modos de vida nas cidades sul-africansas nos convidam a refletir sobre a complexidade daquilo que o fotógrafo chama de "intimidade e compromisso com estes contextos e pessoas". Neto nasceu na township de Alexandra, em Joanesburgo, no mesmo ano que o líder sul-africano Nelson Mandela foi libertado, após os vinte e sete anos de prisão, ou seja, quatro anos antes do fim do apartheid e da retomada da democracia no país. Afirma ter como referência fotógrafos documentais negros como Peter Mugubane, Bob Gosani e Ernest Cole, sobretudo pelo modo como manejavam as imagens que denunciavam o cotidiano de segregação da população negra durante o apartheid. “Essas foram as primeiras que tive acesso e me motivaram a fotografar as ruas de Joanesburgo e as formas como as pessoas ocupam esses espaços" (NETO, 2020).

As imagens de Kgomotso Neto nos convidam a mergulhar nas novas dinâmicas políticas e estéticas que ultrapassam as barreiras materiais e simbólicas

3 A escritora e ativista negra norteamericana Gloria Jean Watkins adotou como pseudônimo o nome da sua bisavó materna, Bell Blair Hooks. A escolha da letra minúscula é uma preferência da autora para as referências das suas obras, justificada pelo interesse da atenção ser concentrada no enfoque ao conteúdo da sua mensagem desenvolvido em suas obras ao invés de em si mesma. Cf. bell hooks. Talking back: Thinking feminist, thinking black. Boston: South End Press, 1989. 
que mantiveram a população negra sul-africana presa a uma opressão durante séculos do colonialismo europeu, reiterada por traumas e cicatrizes de quatro décadas de apartheid. Como o filósofo e cientista político camaronês Achille Mbembe (2001) mencionou, a escravidão, a colonização e o apartheid foram fatores que serviram para "unificar o desejo africano de se conhecer a si mesmo, de reconquistar seu destino (soberania) e de pertencer a si mesmo no mundo (autonomia)" (MBEMBE, 2001, p. 176). Essa retomada, após o alterocídio - como Mbembe chamou a estratégia do outro ameaçador - , tem possibilitado a jovens artistas como Neto produzir formas visuais e narrativas que reabilitam as diversas formas de afeto e de reapropriação, pelos corpos negros, dos centros urbanos e dos hábitos dos antigos territórios segregados.

Porém, por estarem situadas no contexto da arte contemporânea, tais formas se afastam do desejo de apenas documentar, reportar ou denunciar questões e problemas que afetaram e afetam toda uma geração. Suas narrativas visuais apostam em jogos sígnicos que partem do registro e da documentação do cotidiano das ruas para fazê-los fabular e contar histórias sobre raça, corpo e poder.

Como veremos, o trabalho de Neto é marcado pelo trânsito por distintas referências e linguagens e por estratégias visuais que mostram aqueles que são sempre vistos mas raramente reconhecidos - como uma mulher empurrando o seu carrinho de legumes pela rua, os taxistas organizando a fila dos viajantes e os catadores de lixo reciclável de Joanesburgo. Interessado nas pessoas que estão nos alicerces da economia informal e nos personagens da vida urbana da África do Sul, Kgomotso Neto é um contador de histórias sul-africanas contemporâneas, que fogem do estereótipo de "culturas primitivas selvagens" criado para o continente africano, no que hooks (2019) chamou de "primitivismo pós-moderno". Suas imagens reconfiguram a "fascinação" e a necessidade estética ocidental de "demarcar claramente sujeito e objeto" (HOOKS, 2019, p. 66) para dar a ver a presença de corpos e modos de vida que embaralham tais demarcações, mostrando o quanto são construídas e impuras.

A hipótese do texto é que, ao se considerar parte de uma geração que documenta tudo que está em sua volta, sob novos arranjos de produção, circulação e legitimação das imagens, o artista decoloniza tanto o olhar sobre diversas experiências ainda não ditas e contidas pelas invisíveis barreiras 
criadas pela segregação racial, quanto as formas de narrá-las. Frantz Fanon (1967) argumenta que a principal arma dos colonizadores era a imposição da imagem dos colonizados sobre o povo subjugado e que, para serem livres, estes deveriam se libertar das imagens depreciativas de si mesmos "usando todos os meios para inverter essa escala, incluindo, é, claro, a violência" (1967, p. 37). Este texto reflete sobre a premissa de que novas lutas por liberdades passam também por revisar estas imagens no campo das artes e nos imaginários sociais e no que Mark Sealy (2019) apresenta como um referencial contemporâneo do modo como algumas culturas vêem a si mesmas, diferente das representações violentas repletas de estereótipos que ativam memórias cristalizadas, ao ressignificar as relações de poder entre "observador e observado" (TAYLOR, 1994, p.36).

Para tanto, o texto apresenta uma abordagem fundamentada teórica e metodologicamente no pensamento decolonial e de autores contemporâneos da história da arte e da fotografia para tratar a imagem como um problema de representação, ou seja, de regulação das relações entre visível e dizível. Neste tipo de abordagem, as imagens não são vistas como simples conteúdos visuais ou "textos" a serem interpretados, mas como fenômeno comunicativo atravessado simultaneamente por questões históricas, culturais, estéticas e políticas.

Com isso, a análise das imagens não se limita apenas a seus aspectos técnicos, formais, visuais e discursivos e são cruzados também com dados de seu extracampo, a partir de informações históricas e do contexto social e político em que estão inseridas. Assim, buscamos evidenciar como as imagens e sua inserção no campo social fazem parte de estratégias de produção de sentido nas quais é a própria representação que está em jogo, nos arranjos intencionados dos aspectos técnicos, estéticos, formais e sociais da imagem.

\section{Estruturas de resistência na arte sul-africana}

1994 é o ano mundialmente conhecido como o fim do regime do apartheid e das "as primeiras eleições presidenciais vencidas por Nelson Mandela, o primeiro presidente negro da história da República da África do Sul" (PAWŁOWSKA, 2017, p. 86). O Congresso Nacional Africano (African National Congress - A.N.C), partido vencedor, anunciaria um programa oficial destinado à construção de um plano multirracial de uma "nação arco-íris", num 
período intensivo de transição política, e de inclusão da diversidade étnica subrepresentada pela dominação da supremacia branca africâner.

Em 1990, mesmo ano em que Mandela foi libertado, Sue Williamson publicou Resistance art in South Africa (1990), em que destaca o papel das artes visuais nas lutas de libertação da África do século XX contra o apartheid. A obra compilava um catálogo de artistas, em sua maioria negros, cujos trabalhos remetem à luta contra o sistema racial repressivo, sendo este um instrumento de demarcação do campo cultural e artístico. "Falar da margem ao centro" (HOOKS, 2019) fez um espaço de repressão se tornar um local de resistência profundamente produtivo e desafiador para uma geração de jovens artistas como Kgomotso Neto. Percorrer esta margem como experiência criativa e subjetiva vem possibilitando a uma geração de artistas e fotógrafos negros contemporâneos sul-africanos produzir uma virada ética e estética em relação aos processos assimilativos coloniais e estereotipados da negritude rebelde ou exótica (RICHARDS, 1994).

A "arte da resistência" foi a referência artística para a geração de Kgomotso Neto, que incorpora essa linguagem como um gênero de expressão que ressignifica conceitualmente os estereótipos e padrões estéticos ocidentais da "fantasia grotesca" (KILOMBA, 2019, p. 114) em torno da negritude. Esse processo possibilitou o surgimento de formas artísticas que refutam uma espetacularização do ativismo e promove importantes reflexões sobre arte e sociedade na África do Sul, como as que foram promovidas nas duas Bienais de Joanesburgo (1995 e 1997). Esse diálogo entre artistas locais e de outros países africanos possibilitou um novo momento para a arte sulafricana, como explica Dona Marimba Richards (1994), em sua tese de uma consciência nacional africana.

A importância desse diálogo deve ser entendida no contexto da argumentação de Mbembe (2001), de que a ideologia racista do apartheid duplicou o peso colonial na África do Sul, negando por muitos anos aos artistas sulafricanos negros o direito à autorrepresentação e à auto-expressão, sem liberdade, história, individualidade e sentido de presença, o que exigiu muita resistência. Neste sentido, uma produção artística que ecoa um pensamento e uma estética decoloniais é relevante na medida em que "rompe com os pensamentos gravados nas mentes e corpos por gerações" (COSTA NETO, 2016, p. 51) e cria formas legítimas de a população negra "finalmente narrar suas próprias fábulas em uma linguagem e voz que não podem ser imitadas, porque são verdadeiramente suas" (MBEMBE, 2001, p. 24). 
Na fotografia, muitos artistas deram uma guinada conceitual em suas formas de produção, seja com a investigação das memórias pessoais e familiares dos álbuns de famílias negras de Santu Mofokeng seja com a utilização do próprio corpo para representar a violência e resistência em um contexto pós-apartheid, em Mohau Modisakeng. As memórias que seguem ativas no pós-apartheid, que Ariella Azoulay (2008) vê como um instrumento que circula no tempo e no espaço, segue perturbando o mundo a partir das suas diversas interações visuais. Mas, como discursividade política, implicam práticas diferenciadas de auto-apresentação, cujo estilo fotográfico envolve "encenação e atuação em cenas que refletem e reconstroem suas experiências cotidianas" (GREEN; THOMAS, 2014, p. 440).

São estas mudanças que alicerçam a nova geração de artistas visuais negros contemporâneos na África do Sul, como Kgomotso Neto, o coletivo I See A Different You, dos fotógrafos Justice Mukheli, Innocent Mukheli e Vuyo Mpantsha (MOKOENA, 2012) ou a artista-ativista Zanele Muholi. Todos atuam a partir da hibridização de mídias e linguagens (fotografia, performance, instalação, internet) e campos de atuação (arte, jornalismo, moda, publicidade) e intervêm no campo político da raça, entrelaçando novas lutas e garantias de liberdade de gênero, sexualidade, juventude e políticas do corpo. A esse respeito, Andrew Van der Vlies considera que "seus projetos compartilham um objetivo arquivístico e um esforço para reunir evidências e testemunhar a vida" (VAN DER VLIES, 2012, p. 94). Como veremos, as imagens desta geração, particularmente as de Kgomotso Neto, mostram uma negritude que nos convida a redescobrir e celebrar uma africanidade diversa e empoderada, através de uma "aesthesis decolonial" (MIGNOLO, 2010) que leva em conta e afirma cognições e sensorialidades locais e não universalizadas, bem como diálogos, presenças, representações, liberdades e formas expressivas que anunciam outros futuros possíveis.

\section{Turning Heads ou o empoderamento e a restituição do corpo}

No projeto Turning Heads (2019), Kgomotso Neto leva para dentro do estúdio fotográfico a experiência de uma africanidade de resistência através de representações performadas da prática que os sul-africanos negros têm de cuidar dos seus cabelos e da sua beleza em salões de rua. A série transporta das ruas para o espaço de produção visual do estúdio fotográfico a experiência ancestral de afirmação de uma beleza negra africana "inferiorizada e subjulgada" (TAYLOR, 1994, p. 66) pela dominação branca. 
Esse gesto de transporte, intencional e autorreflexivo, típico da experiência da imagem na fotografia contemporânea (FRIED, 2012), desloca não apenas a experiência de um ethos, mas também sua forma de reconhecimento e de visibilidade no campo social. Ao emprestar aos retratos posados as marcas do glamour da moda e da artificialidade do estúdio, Neto reconstrói o valor e as formas de apreciação de corpos e modos de vida.

Na figura abaixo (Figura 1), vemos uma mulher jovem negra de pé, descalça, vestida com um tailleur rosa e luvas brancas, que passa a máquina no cabelo de um rapaz sentado, também descalço, usando uma calça comprida rosa. Aos pés do rapaz, uma garrafa plástica contém um composto utilizado para higienizar as máquinas e a cabeça, depois de raspada. Diante de um fundo infinito liso em um tom de rosa bem suave, a mulher olha frontalmente para a câmera, enquanto o rapaz tem o rosto levemente virado paro o lado e para baixo.

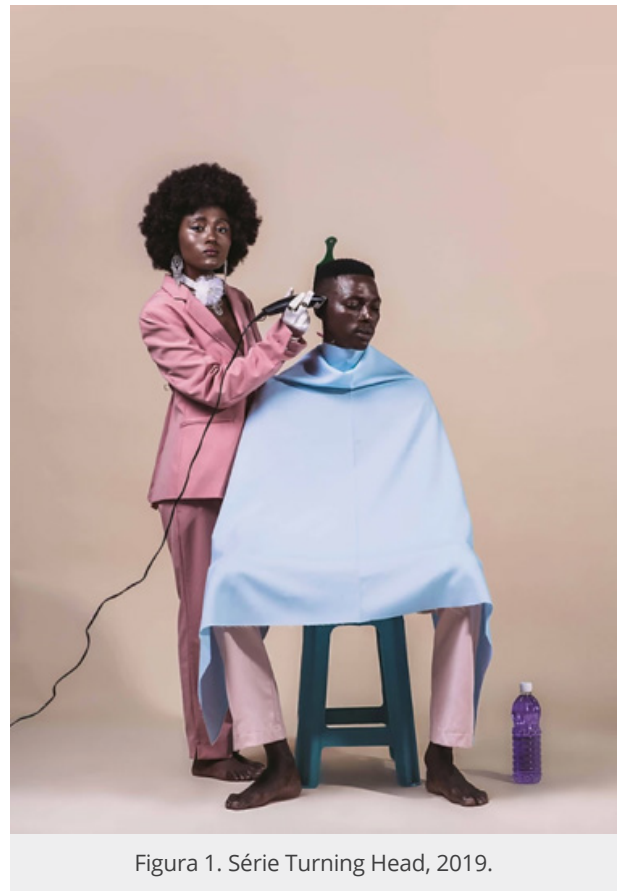

Interessante observar que essa e nas outras imagens da série não há um tom de vitimização ou uma representação direta de denuncismo. Há consciência de si e do significado dos signos. O olhar de dignidade, altivez e elegância 
investidos de glamour conferem à cena um ar de ironia e bom- humor com o qual Neto desconstrói as narrativas do embranquecimento, que estão ali para serem desmontadas. A imagem oferece novas articulações de representação da negritude, distintas do papel colonizador tradicional da fotografia no mundo ocidental que enquadra as culturas negras de forma generalizada e deturpada onde "as suas vidas só podem vir a existir através da manutenção dos padrões da branquitude" (SEALY, 2019, p. 195).

Isso fica claro também em outras imagens da série ${ }^{4}$, onde o mesmo casal posa frontalmente para a câmera com o mesmo olhar empoderado, ao lado de objetos que pertencem às estratégias de "embelezamento" do cabelo, como escovas e produtos químicos habituais na experiência sul-africana nos salões de beleza. Ou então ambos aparecem segurando cabeças de manequins brancos com perucas de cabelos negros, porém lisos, como um ideal supostamente a ser alcançado. Mas há uma imagem da série em que esse gesto autorreflexivo, irônico e consciente da violência simbólica, fica especialmente visível. Nela o mesmo casal aparece sentado atrás de uma mesa. Ambos estão com as mãos postas sobre a mesa, deixando aparecer apenas seus torsos. O do rapaz, nu, e o da mulher, vestido com um tailleur verde com um grande corte que deixa entrever seu colo. Mas o que chama a atenção é que ambos aparecem com uma peruca de cabelos negros e lisos viradas para frente, tapando-Ihes todo o rosto (Figura 2). Do lado direito da mulher, apoiados sobre a mesa, dois tubos de cremes alisantes parecem lembrar que o alisamento tira a identidade e esconde a negritude.

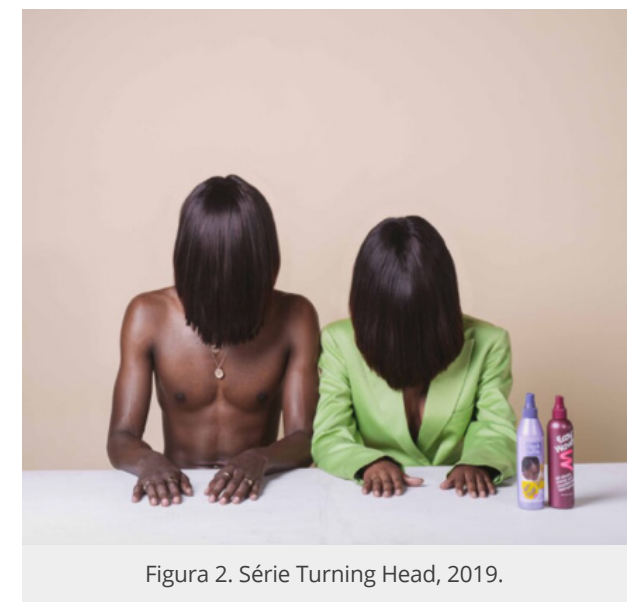

4 Disponível em: <https://www.behance.net/gallery/81521009/Turning-Heads>. Acessado em: $1 / 8 / 2020$. 
As imagens da série constituem um ato poético de resistência fabulatória (NYONG'O, 2019) na medida em que deslocam o imaginário social de inferioridade e a violência estética e subjetiva que a branquitude forjou para a pele e o cabelo negros como o lugar do "feio", através da afirmação das práticas cotidianas do cuidado de si e da beleza negra enquanto valor cultural e político. Turning Heads é sobre blackness e sobre como black is beautiful. No caso das imagens de Neto, esse reprocessamento conceitual é taticamente realizado pelo cruzamento das linguagens da pose no retrato, com todos seus códigos e estratégias artificiais de produção do sujeito; da linguagem da moda, de onde o artista retira o recurso da ficcionalização e da invenção de corpos; e da performance como gênero artístico que promove justamente a reencenação do corpo como construção cultural a ser ressignificada.

Mas Neto faz aparecer em quase todas as imagens da série um outro elemento igualmente importante para seu gesto de profanação da violência da branquitude: faz coexistir tanto o imaginário de glamour da moda quanto o imaginário da rua, na figura do banquinho de plástico no qual se senta a personagem masculina, cuja cabeça está virada (Figura 1). Ao mesmo tempo, a frontalidade do olhar da personagem feminina que raspa o cabelo do rapaz nos interpela de forma decisiva. Essas coexistências - a encenação de uma prática popular de rua como se fosse um editorial de moda que vai do glamouroso ao tosco; e uma cabeça virada e outra que nos olha frontalmente - é que talvez tornem possível a Neto, em certa medida, profanar e restituir, no sentido agambeniano, a experiência de negritude ao uso comum dos homens (AGAMBEN, 2007). No caso, ao próprio povo negro e sua história.

Curiosamente, os gestos de profanação de Neto não se restringem ao campo da arte. Os recursos da performance, da pose e das referências à moda são usados também em diversos outros trabalhos menos claramente "ativistas", como o ensaio de ficção científica Bantu Space Odissey. Este bem poderia fazer parte de seus trabalhos comerciais como fotógrafo freelancer de campanhas publicitárias, como a "Coca-cola 2019", onde a imagem do produto revela uma juventude negra empoderada e colorida nas townships, ou de trabalhos comissionados para revistas de moda e festivais de música.

Chama a atenção aí o trânsito que Neto faz por diversos campos: arte, moda e publicidade. Ele não apenas se apropria das referências a esses campos, como também efetivamente opera um cruzamento entre eles. Talvez não seja por acaso que em seu website <https://kgomotsoneto.co/> Neto se 
auto-intitule "fotógrafo" e não "artista" e não crie categorias específicas que rotulem suas imagens, separando-as em domínios específicos ou hierarquizados. Estão lá em igualdade de condições os trabalhos mais poéticos, os documentais e os comerciais, identificados apenas por seus títulos.

De certa forma, Neto parece estar ciente de que definições e fronteiras não são naturais, seja na arte ou na vida. Parece estar ciente também de que as imagens são elas próprias impuras e contaminadas por distintas referências. Neto fala a língua das ruas e das instituições da arte e do mercado. Porque ele próprio transita e é híbrido, não se restringindo a um único campo de atuação, é que suas imagens talvez alcancem a condição de um dispositivo profanador que reinventa os imaginários da negritude e da africanidade.

\section{Taxi Rank ou a apropriação e a restituição do espaço}

Mas esses imaginários são construídos não apenas a partir da apropriação das referências do retrato, da moda ou da publicidade. Neto também fabula (NYONG'O, 2019) a africanidade através de suas paisagens urbanas e rurais. Tendo sido influenciado por fotojornalistas negros como Mugubane, Cole e Gosani e trabalhado por algum tempo como fotógrafo free-lancer para jornais de Joanesburgo, usa também a linguagem da fotografia documental e de rua para produzir representações do lugar onde vive.

Se em suas paisagens rurais, é da relação com as memórias afetivas, com a terra e com a ancestralidade que se trata, em suas paisagens urbanas as documentações da vida e da cultura urbanas de Joanesburgo vão contar histórias atuais do povo para o próprio povo. Sejam nos registros dos protestos de estudantes em 2015, contra o aumento das taxas acadêmicas, ou nas imagens do cotidiano da cidade, o estilo de vida urbano da população negra sul-africana é construído pelas lentes da fotografia de rua. A fotografia de rua é uma tradição documental que tentou produzir um olhar criativo e original da banalidade cotidiana para construir um enorme arquivo visual da experiência sensível da vida nas cidades modernas. Mas, nas experimentações contemporâneas da arte, apesar de guardar forte ressonância com a estética da fotografia documental e jornalística, esses arquivos ultrapassam o registro do "isso-foi" ou do "isso-é" em favor do destaque da qualidade acontecimental daquilo que cartografam: os processos socioculturais, históricos, políticos e subjetivos.

Um trabalho onde isso pode ser observado é a série Taxi Rank, realizada desde 2013 e que foi exibida em 2019 no centro de Joanesburgo. Os taxis 
(no caso, vans) são a principal forma de transporte coletivo da África do Sul. São eles que fazem a ligação diária de milhares de pessoas das townships e subúrbios para o centro. Nos tempos do apartheid, o centro era um lugar rico, ordenado, asséptico e proibido para a comunidade negra, que necessitava de um documento de permissão para trabalhar ou circular nas áreas destinadas aos brancos (BLASER et al., 2010).

Na Joanesburgo de hoje, os brancos migraram para os subúrbios e os negros ocuparam o centro e reganharam o direito de ir e vir. Mas, os legados do apartheid e do modelo econômico neoliberal para a mobilidade foram uma cidade sem um sistema público de transporte coletivo organizado. Por isso mesmo, os taxis compartilhados cumprem um papel central na vida de milhares de africanos negros, mestiços e imigrantes que circulam diariamente na cidade e nas townships.

Em seu conjunto, as imagens de Taxi Rank não abordam apenas os taxis coletivos e o embarque e desembarque de passageiros como questão de mobilidade. Mostram também a van como um personagem que faz parte do imaginário sul-africano, da economia local, da cultura urbana e do modo de vida dos não-brancos. Na figura abaixo (Figura 3), a cena de um ponto de vans mostra exatamente essa confluência da van com a economia informal e com a agitação da cidade.

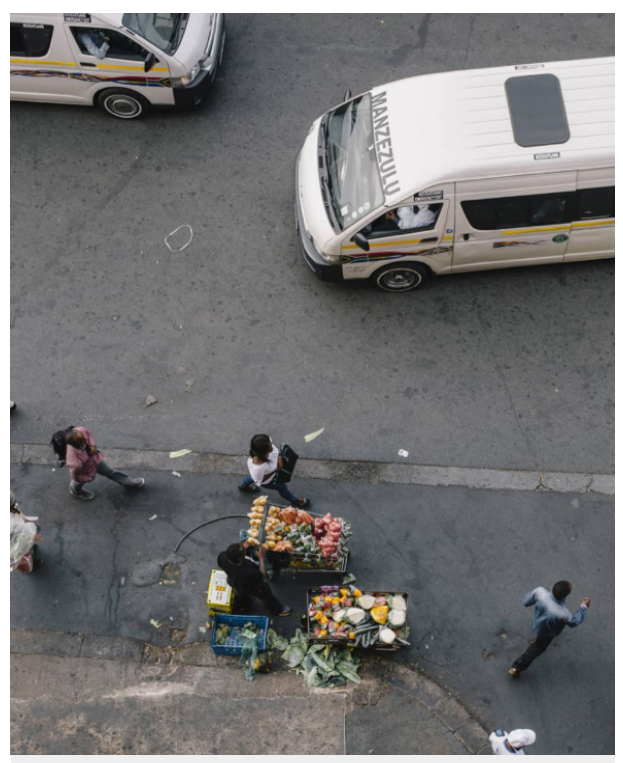

Figura 3. Série Bree Taxi Rank, 2019. 
Mas, aqui, a imagem não busca mostrar o todo, e sim os detalhes, as nuances, as invisíveis coisas visíveis do dia-a-dia, aquilo que faz cultura e denota identidade. Nota-se também os usos dos enquadramentos e a escolha de distribuição dos elementos como forma de sincronizar esses vários eventos que confluem na imagem. Ponto de vista, orientação vertical e modo de enquadrar/cortar são estratégias que aparecem com frequência na série ${ }^{5}$ para chamar a atenção para presença da imagem como representação e, ao mesmo tempo, para a performance das ruas.

Em sua documentação das ruas, as imagens mostram também a performance do social: os percursos feitos pelo próprio artista no interior das vans; as garagens onde ficam estacionadas, em acordo com as máfias locais; as oficinas mecânicas no centro da cidade e nas townships. Essas paisagens mostram, finalmente, a liberdade de circulação e o direito dos negros à cidade e suas formas de ocupação dinâmica e informal. Dão a ver todo um universo social que aponta para as reconfigurações da vida sul-africana pós-apartheid e, ao mesmo tempo, para as marcas do passado colonial.

Mas o que chama a atenção especificamente na exposição Bree Taxi Rank (2019) é o fato de algumas dessas imagens terem sido impressas e exibidas na rua, nos pontos das vans, onde os passageiros passam e aguardam às vezes muito tempo por elas. Ou dentro das garagens, onde por vezes ficam guardadas. A instalação das imagens no próprio espaço do objeto da representação constitui também um forte gesto de restituição (Figura 4), na medida em que Neto usa o lugar para potencializar a experiência de fruição das imagens por meio de um reconhecimento auto-reflexivo.

Em entrevista ao site cultural OkAfrica em novembro de 2019, o artista afirma que elas estão lá para as pessoas interagirem e que elas não são protegidas por uma moldura, como numa galeria ou em um museu. Afixadas como banners, podem ser rasgadas ou pichadas. Segundo ele, é assim com a vida que se leva nesses lugares, precária e frágil. Mas o gesto da instalação sitespecific ${ }^{6}$ significa também tornar a arte acessível às pessoas comuns e de dar uma chance de elas pararem um pouco durante os trajetos. Uma forma de tornar visível a matéria e os signos que constituem parte de suas vidas.

5 Disponível em: <https://www.okayafrica.com/south-african-photographer-exhibits-photos-at-taxi-rank/>. Acessado em 1/8/2020.

$6 \mathrm{Na}$ arte contemporânea, o termo site-specific remete à experiência de uma obra que tem uma relação contígua com o local onde é instalada e na qual o local passa a fazer parte também da obra por conta deste tipo de relação. Cf. Ardenne, P. Un art contextuel. Paris: Flamarion, 2004. 


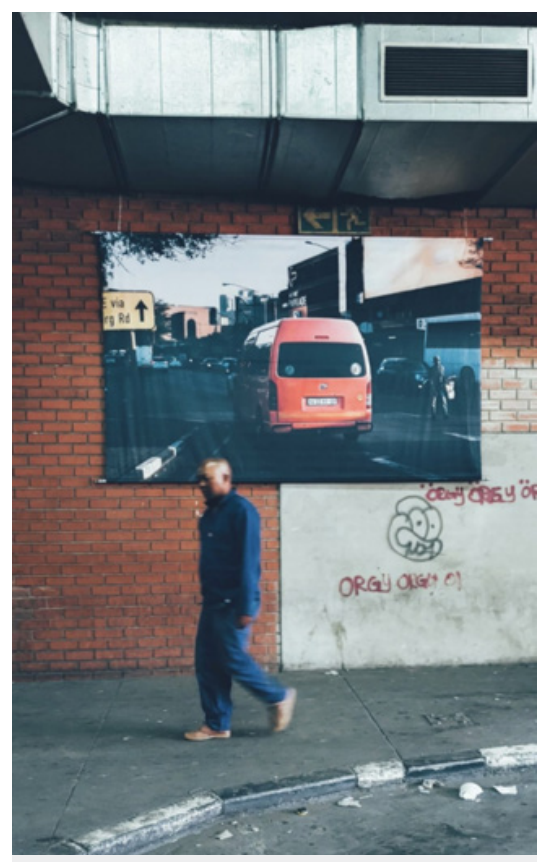

Figura 4. Série Bree Taxi Rank, 2019.

Fazer parar, fazer ver. Apropriar-se do espaço e das imagens. Apropriar-se de uma africanidade e de uma negritude desejadas. Os trabalhos de Neto são, como ele afirma, para todos. Mas dialoga diretamente com a população negra sul-africana. Não que isso o afaste do espaço das galerias e do mercado de arte. Mas até nesse caso é possível perceber os rastros da segregação racial na África do Sul na atualidade. Como jovem artista, Neto tem sido atualmente convidado para expor em galerias em áreas majoritariamente negras. Por um lado, isso seria coerente com seu desejo de contar histórias de seu povo para seu povo. Por outro, deixa entrever as barreiras materiais e simbólicas ainda existentes na Joanesburgo pós-apartheid que desafiam Neto a continuar a lutar e a r/existir. Seus projetos tornam esses espaços uma arena de discussão política e estética sobre o corpo, a cidade, a negritude, que recusa os estereótipos do afro-pessimismo 7 (VAN DER VLIES, 2012). Constituem um trabalho que deve ser de fato interpretado como "africano", que sai dos regimes lineares de temporalidades e confabula as diferenças, identificando novas formas e articulações de poder. 


\section{Conclusão}

É a partir de imagens íntimas do cotidiano com que cresceu e se relaciona e de uma documentação por vezes direta, por vezes encenada, que Kgomosto Neto incorpora múltiplas versões de si mesmo, de seus diversos atravessamentos de linguagens e experiências de vida. Retratar seu cotidiano faz parte de um jogo de registro e de encenação que pressupõe um artificio de autoconstrução e uma estratégia para compreender a si mesmo e sua ancestralidade. Assim, como explica Mokoena (2012), essa geração de jovens artistas negros sul-africanos cresceu acreditando em si mesmos e que podem fazer muitas coisas.

As imagens de Neto e de muitos outros fotógrafos e fotógrafas negros(as) tentam encenar a subjetividade sul-africana contemporânea através de um complexo jogo de exclusão, memória, crença, lutas, história e cultura urbana e negra. $\mathrm{O}$ artista forja um novo vocabulário visual ao testar os limites da representação e do representável, ao afirmar compromissos com diversos marcadores de identidade negra africana e seus elementos materiais e simbólicos. Suas fotografias falam de tensões entre invenção e tradição, a partir de uma lente direcionada ao cotidiano de uma cultura pública sul-africana que está saturada de efeitos associados a trauma do apartheid. Falam também, implicitamente, de uma infinidade de outras histórias, em torno da xenofobia de imigrantes de outras partes da África, do subemprego e da pobreza da população negra, quando vemos em suas imagens uma senhora vendendo verduras na rua, um ambulante ou um cobrador de transporte coletivo, resultante das políticas econômicas neoliberais.

Os traumas são explorados a partir de novas formas de narrativa, ao reabilitar de maneira diversa um afeto à cidade e aos antigos territórios segregados que se recusam a ser espetacularizados, seja na forma poética dos fotógrafos do período do apartheid ou do realismo direto do Bang Bang Club ${ }^{8}$, que podem também fazer apagar e calar uma narrativa ao invés de fazê-la circular e se expor. Confrontar o espectador com o centro urbano de Joanesburgo ou com os estilos de corporeidade da juventude negra passa por uma estratégia política de fazer circular suas imagens tanto nos espaços populares e de arte familiares aos negros quanto nos espaços da elite cultural branca sul-africana, seja na internet, em comerciais de TV ou em editoriais de moda. 
Essas imagens possibilitam uma revisão estética, a partir de uma representação fotográfica decolonial que oferece uma linguagem em torno do afeto e de uma afiliação culturais. Desde o centro urbano ocupado, as townships que durante muito tempo foram reconhecidas como um espaço de protestos, heróis e lutas, estas paisagens e personagens retratados em suas fotografias reconstroem um lugar repleto de significação de beleza, estilo de vida, moda e liberdade. Mais do que simplesmente serem mostradas ou vistas, seus personagens e paisagens querem ser desejadas e vistas como tentativas de atravessamentos e deslocamentos de identidades forjadas pelo colonialismo.

Fernando Gonçalves é professor da Faculdade de Comunicação da Uerj e do PPGCOM-Uerj, bolsista de produtividade do CNPq e artista visual. É doutor em Comunicação e Cultura pela UFRJ e Pós-doutor em Sociologia do Cotidiano pela Universidade Paris V. Foi professor convidado na Universidade de Montpellier III e pesquisador visitante na Universidade de Bari. Foi diretor da Faculdade de Comunicação Social e coordenou o GT de Estudos de Cinema, Fotografia e Audiovisual da Compós. Coordena, desde 2010, o Grupo de Pesquisa TRAMA.

goncalvesfernandon@gmail.com

Daniel Meirinho é professor do departamento de Comunicação Social da Universidade Federal do Rio Grande do Norte e do Programa de Pós-graduação em Estudos da Mídia. Realizou pós-doutorado em Comunicação pelo Programa de Pós-Graduação em Comunicação da Universidade Estadual do Rio de Janeiro. É doutor em Ciências da Comunicação pela Universidade Nova de Lisboa. É pesquisador do Grupo Pragmáticas da Comunicação (PRAGMA-UFRN).

danielmeirinho@hotmail.com

Contribuições de cada co-autor: Fernando: concepção da estrutura da pesquisa, construção metodológica, elaboração do guia da entrevista, análise das entrevistas, análise formal do corpus, escrita, revisão e edição do manuscrito; Daniel: concepção da pesquisa, coleta e curadoria de dados, entrevista e pesquisa de campo, análise formal do corpus, construção metodológica, construção de figuras, escrita, revisão e edição do texto. 


\section{Referências}

AGAMBEN, G. Profanações. São Paulo: Boitempo, 2007.

AZOULAY, A. The Civil Contract. New York: Zone Books, 2008.

BIKITSHA, D. Preface. In: Tauza - Bob Gosani's People. MASIZA, J. J.; MUTSOATSE, M., p. 11-13. Cape Town: Struik, 2005.

COSTA NETO, A. G. A Denúncia de Cesáire ao Pensamento Decolonial. Revista EIXo, Brasília - DF, v. 5, n. 2, julho-dezembro de 2016.

FANON, F. Pele negra, máscaras brancas. Salvador: EdUFBa, 2008.

The wretched of the earth. Grove Press: Nova York, 1967.

FRIED, M. Why Photography matters as art as never before. 4th ed. New Haven and London: Yale University Press, 2012.

GREEN, L.; THOMAS, K. A density of texture: reading photography from South, North and West Africa. Social Dynamics, 40:3, 439-443, 2014.

HALL, S. Cultura e representação. Rio de Janeiro: PUC-Rio - Apicuri, 2016.

HOOKS, B. Olhares negros: raça e representação. Tradução de Stephanie Borges. São Paulo: Elefante, 2019.

KILOMBA, G. Memórias da plantação: episódios de racismo cotidiano. Rio de Janeiro: Editora Cobogó, 2019.

MBEMBE, A. As formas africanas de auto-inscrição. Estudos Afro-asiáticos. Rio de Janeiro, v. 23, n. 1, pp. 171-209, 2001.

MIGNOLO, W. D. Aiesthesis decolonial. CALLE 14: revista de investigación en el campo del arte, v. 4, n. 4, p. 10-25, 2010.

Habitar la frontera. Sentir y pensar la descolonialidad (Antología, 1999-2004). Barcelona: CIDOB y UACI, 2015.

MOKOENA, $\mathrm{H}$. I see a different you: township aesthetics, fashion and the emergence of selfrepresentational photography in post-apartheid South Africa. African Studies Workshop, Harvard, October 15. 2012. Disponível em: <https://vimeo.com/56027142>. Acessado em 25 de janeiro de 2020.

NETO, K. Estratégias e discursos visuais. [Entrevista concedida à Daniel Meirinho], Joanesburgo, 16 de jan. 2020.

NYONG'O, T. Afro-Fabulations: The Queer Drama of Black Life. New York UP, 2019.

QUIJANO, A. Colonialidade, poder, globalização e democracia. Novos rumos, v. 37, n. 17, p. 4-28, 2002. 
RICHARDS, D. M. The African Aesthetic and National Consciousness. In: WELSH-ASANTE, K. (ed.). The African aesthetic: keeper of the traditions. London: Praeger, 1994.

SEALY, M. Decolonizing the Camera: Photography in Racial Time. Londres: Lawrence e Wishart, 2019.

STEYN, M. Whiteness Just Isn't What it Used to be: white Identity in a Changing South Africa. Albany, State University of New York Press, 2001.

TAYLOR, C. The politics of recognition. In: TAYLOR, C.; GUTMANN, A. (eds), Multiculturalism: Examining the Politics of Recognition, Princeton, NJ: Princeton University Press, 25-74, 1994.

VAN DER VLIES, A. Art as archive: Queer activism and contemporary South African visual cultures. Kunapipi, v. 34, n. 1, p. 10, 2012.

Artigo recebido em 03/09/2020 e aprovado em 28/11/2020. 